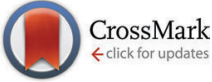

Cite this: Phys. Chem. Chem. Phys., $2016,18,10719$

Received 19th November 2015, Accepted 14th December 2015

DOI: $10.1039 / c 5 c p 07115 a$

www.rsc.org/pccp

\title{
Improved charge carrier separation in barium tantalate composites investigated by laser flash photolysis
}

\author{
Jenny Schneider, ${ }^{* a}$ Konstantin Nikitin, ${ }^{\text {ab }}$ Michael Wark, ${ }^{c}$ Detlef W. Bahnemann ${ }^{a b}$ \\ and Roland Marschall*d
}

\begin{abstract}
Charge carrier dynamics in phase pure $\mathrm{Ba}_{5} \mathrm{Ta}_{4} \mathrm{O}_{15}$ and in a $\mathrm{Ba}_{5} \mathrm{Ta}_{4} \mathrm{O}_{15}-\mathrm{Ba}_{3} \mathrm{Ta}_{5} \mathrm{O}_{15}$ composite have been studied by means of diffuse reflectance laser flash photolysis spectroscopy in the presence and absence of an electron donor, in order to reveal the reason for the improved photocatalytic performance of the latter. For the first time the transient absorption of trapped electrons with a maximum at around $650 \mathrm{~nm}$ and of trapped holes with a transient absorption maximum at around $310 \mathrm{~nm}$ is reported for tantalates. The decay kinetics of the photogenerated charge carriers could be fitted by second order reaction kinetics, and the direct recombination of the trapped electrons with the trapped holes was proven. In the absence of an electron donor, no difference in the decay behavior between the phase pure material and the composite material is found. In the presence of methanol, for the pure phase $\mathrm{Ba}_{5} \mathrm{Ta}_{4} \mathrm{O}_{15}$ the recombination of the charge carriers could not be prevented and the trapped electrons also recombine with the ${ }^{\bullet} \mathrm{CH}_{2} \mathrm{OH}$ radical formed via the methanol oxidation by the trapped holes. However, in the composite, the electron can be stored in the system, the ${ }^{\bullet} \mathrm{CH}_{2} \mathrm{OH}$ radical injects an electron into the conduction band of the second component of the composite, i.e., $\mathrm{Ba}_{3} \mathrm{Ta}_{5} \mathrm{O}_{15}$. Thus, the electrons are available for an extended period to induce reduction reactions.
\end{abstract}

\section{Introduction}

Solar hydrogen $\left(\mathrm{H}_{2}\right)$ is considered as an efficient solar fuel for future energy applications. ${ }^{1}$ Among the different strategies to generate $\mathrm{H}_{2}$, photocatalysis is one interesting approach, which has been investigated intensely in the last few decades. ${ }^{2,3}$ In fact, charge carrier generation upon light irradiation and their transfer in semiconductor materials to reduce and oxidise electrolytes have been studied in detail for many years. ${ }^{4}$ As a dream reaction, the photocatalytic overall water splitting into $\mathrm{H}_{2}$ and molecular oxygen $\left(\mathrm{O}_{2}\right)$ would be ideal, however, $\mathrm{O}_{2}$ generation is severely hampered by the necessary four electron transfer needed for water oxidation.

Thus, biomass derivatives such as methanol as hole reactants are often employed in photocatalytic $\mathrm{H}_{2}$ generation experiments. ${ }^{5}$ Methanol was proven to act as a sacrificial agent in such systems

\footnotetext{
${ }^{a}$ Leibniz University Hannover, Institute of Technical Chemistry, 30167 Hannover, Germany. E-mail: schneid@iftc.uni-hannover.de

${ }^{b}$ Saint-Petersburg State University, Laboratory "Photoactive Nanocomposite Materials", Saint-Petersburg, 198504 Russia

${ }^{c}$ Carl von Ossietzky University Oldenburg, Institute of Chemistry, 26129 Oldenburg, Germany

${ }^{d}$ Justus-Liebig-University Giessen, Institute of Physical Chemistry, 35392 Giessen, Germany. E-mail: roland.marschall@phys.chemie.uni-giessen.de
}

with no water splitting occurring and $\mathrm{H}_{2}$ evolving from water. ${ }^{6}$ The fast reaction of photogenerated holes with methanol is another advantage. ${ }^{7}$ Generally, more than $90 \%$ of the generated charge carriers recombine in picoseconds after generation. ${ }^{8}$ By a fast reaction of methanol with holes, less electron hole recombination preserves large $\mathrm{H}_{2}$ yields.

Another strategy to reduce charge carrier recombination is the formation of multiphase or multicomponent heterojunctions, the most famous example being Evonik Aeroxide P25 consisting of anatase and rutile $\mathrm{TiO}_{2} \cdot{ }^{9}$ Many other different material composites have been investigated recently, including a $\mathrm{Ba}_{5} \mathrm{Ta}_{4} \mathrm{O}_{15}-\mathrm{Ba}_{3} \mathrm{Ta}_{5} \mathrm{O}_{15}$ composite system. ${ }^{10}$

$\mathrm{Ba}_{5} \mathrm{Ta}_{4} \mathrm{O}_{15}$ is a highly active water splitting photocatalyst upon UV illumination when modified with a co-catalyst. ${ }^{11}$ Its layered structure can be doped efficiently with nitrogen from the gas phase, leading to an extraordinary band gap reduction from 4.5 down to $1.8 \mathrm{eV} .^{12}$ To further improve its activity, different sol-gel synthesis methods have been developed to enlarge the surface area of $\mathrm{Ba}_{5} \mathrm{Ta}_{4} \mathrm{O}_{15} \cdot{ }^{10,13}$ By employing EDTA and citric acid as complexing agents, Marschall et al. also investigated the formation of the above mentioned composite system in situ. ${ }^{10}$ The composite showed higher photocatalytic activity both in terephthalic acid hydroxylation and in $\mathrm{H}_{2}$ generation without a co-catalyst, compared to 
phase-pure $\mathrm{Ba}_{5} \mathrm{Ta}_{4} \mathrm{O}_{15}$ prepared via a solid-state reaction or sol-gel preparation. The authors explained the higher activity by assuming reduced charge carrier recombination by enhanced electron lifetimes due to electron transfer being probable from $\mathrm{Ba}_{5} \mathrm{Ta}_{4} \mathrm{O}_{15}$ to $\mathrm{Ba}_{3} \mathrm{Ta}_{5} \mathrm{O}_{15}$. In order to prove these assumptions, we have now performed laser-flash photolysis experiments with both, pure $\mathrm{Ba}_{5} \mathrm{Ta}_{4} \mathrm{O}_{15}$ and the $\mathrm{Ba}_{5} \mathrm{Ta}_{4} \mathrm{O}_{15}-\mathrm{Ba}_{3} \mathrm{Ta}_{5} \mathrm{O}_{15}$ composite systems.

Laser flash photolysis is a well-known technique to investigate charge carrier trapping and lifetimes. ${ }^{14}$ In laser flash photolysis experiments a laser pulse initiates different chemical reactions, the kinetics of which are spectroscopically monitored by a flash lamp fired at a known delay after the laser pulse. The study presented in this paper has been performed on opaque samples, where the change in the level of diffusely reflected light after the laser excitation is monitored. A major advantage of the diffuse reflectance laser flash photolysis technique is that the obtained results can be directly correlated with the outcome of the photocatalytic tests, since in both systems powdered samples are applied.

The laser excitation of phase pure $\mathrm{Ba}_{5} \mathrm{Ta}_{4} \mathrm{O}_{15}$ and composite $\mathrm{Ba}_{5} \mathrm{Ta}_{4} \mathrm{O}_{15}-\mathrm{Ba}_{3} \mathrm{Ta}_{4} \mathrm{O}_{15}$ leads to the formation of electronhole pairs:

$$
\mathrm{Ba}_{5} \mathrm{Ta}_{4} \mathrm{O}_{15} / \mathrm{Ba}_{5} \mathrm{Ta}_{4} \mathrm{O}_{15}-\mathrm{Ba}_{3} \mathrm{Ta}_{5} \mathrm{O}_{15} \stackrel{h \nu}{\longrightarrow} \mathrm{h}_{\mathrm{VB}}{ }^{+}+\mathrm{e}_{\mathrm{CB}}{ }^{-}
$$

A part of the formed charge carriers recombine, while the surviving electrons and holes migrate to the surface, where they can be trapped. According to the published studies on tantalates the trapping of the electron can lead to the formation of $\mathrm{Ta}^{4+}$ centers ${ }^{15,16}$

$$
\mathrm{e}_{\mathrm{CB}}^{+}\left(\mathrm{Ta}^{5+}\right) \rightarrow \mathrm{e}_{\mathrm{tr}}{ }^{-}\left(\mathrm{Ta}^{4+}\right)
$$

The hole trapping in mixed oxides such as tantalates can result in the generation of $\mathrm{O}^{\bullet-} /{ }^{\bullet} \mathrm{OH}$ radicals:

$$
\mathrm{h}_{\mathrm{VB}}{ }^{+}\left(\mathrm{O}_{\mathrm{s}}^{2-} /{ }^{-} \mathrm{OH}\right) \rightarrow \mathrm{h}_{\mathrm{tr}}^{+}\left(\mathrm{O}_{\mathrm{s}}^{\bullet-} / \bullet \mathrm{OH}\right)
$$

The trapped charge carriers can either react with the molecules adsorbed on the surface or recombine with each other:

$$
\mathrm{e}_{\mathrm{tr}}{ }^{-}+\mathrm{h}_{\mathrm{tr}}{ }^{+} \rightarrow \text { energy }
$$

In the laser flash photolysis experiments the absorption of the transient species formed after the excitation is detected. This transient absorption is related to certain transitions. In the case of semiconductors the optical transition can be correlated with an electron transfer from the trapped states to the conduction band. The addition of electron acceptors or donors can quench the transient absorption, since the trapped charge carriers are rather transferred to the added reactants allowing the identification of the obtained transient absorption signals of the trapped electrons or holes, respectively.

Since tantalates have been rarely investigated with time-resolved spectroscopic techniques a clear identification of the charge carriers formed is needed. Therefore, herein the transient absorption spectra of phase pure $\mathrm{Ba}_{5} \mathrm{Ta}_{4} \mathrm{O}_{15}$ and composite $\mathrm{Ba}_{5} \mathrm{Ta}_{4} \mathrm{O}_{15^{-}}$ $\mathrm{Ba}_{3} \mathrm{Ta}_{4} \mathrm{O}_{15}$ were recorded in the presence of methanol acting as an electron donor or rather a hole acceptor. ${ }^{6,17}$ Reaction (5) presents the expected photo-induced process:

$$
\mathrm{CH}_{3} \mathrm{OH}+\mathrm{h}_{\mathrm{tr}}^{+} \rightarrow{ }^{\bullet} \mathrm{CH}_{2} \mathrm{OH}+\mathrm{H}^{+}
$$

Moreover, under an inert atmosphere the lifetime of the trapped charge carriers formed in the composites is compared to the charge carrier lifetime generated in the phase pure material.

\section{Experimental details}

Samples for laser flash photolysis measurements were prepared according to the literature. ${ }^{10}$

Fig. 1 illustrates the time-resolved diffuse reflection laser flash photolysis set-up used for this study. The excitation of the sample proceeds with an excimer laser (LPX 200) provided by Lambda Physik. The laser generates pulses of light with a wavelength of $248 \mathrm{~nm}$ and a duration of $20 \mathrm{~ns}$. The laser energy per pulse is $30 \mathrm{~mJ}$ (determined with ferrioxalate actinometry). In the diffuse reflectance experiments the laser beam enters the sample at an oblique angle. The angle of the laser beam path can be adjusted by rotating the Pellin-Broca prism beam steering module. The change in the reflectance is monitored using a laser flash photolysis spectrometer LKS 80 from Applied Photophysics. The light absorption of the photo-generated transient species is analyzed using a $150 \mathrm{~W}$ xenon arc lamp. The pulsing of the xenon lamp for $1.5 \mathrm{~ms}$ by a capacitor discharge leads to a 50-fold increase of the analyzing light intensity. A diffuse reflectance accessory is employed to steer the incoming xenon light beam (via two plane folding mirrors) in relation to the main optical axis. A Spectrosil ${ }^{\mathbb{R}}$ lens focuses the optical beam onto the solid sample. The diffusely reflected light from the sample is collected by a second lens. The third folding mirror reflects the converging beam to the monochromator. Subsequently, the monochromator light falls into the photomultiplier detector (Hamamatsu R928 photomultiplier) where it produces a current. The photometric light level falling on the photomultiplier is kept at $100 \mathrm{mV}$ for all measurements by applying the required high voltages of 550-800 V. The current output from the photomultiplier is terminated by the variable signal terminator (set to $100 \Omega$ )

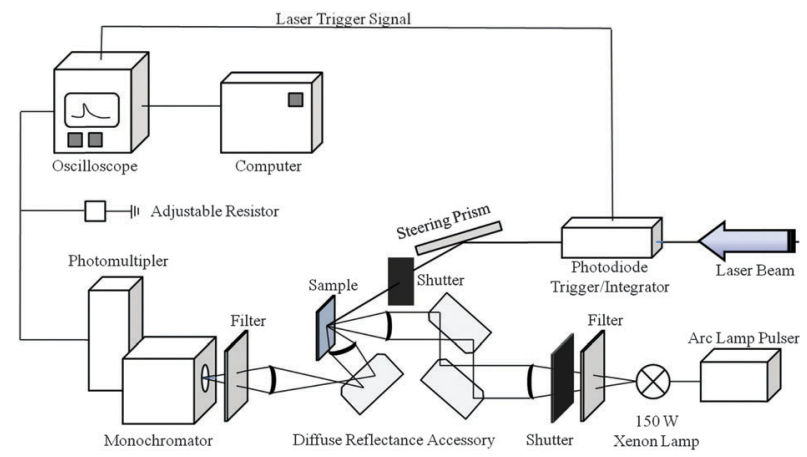

Fig. 1 Schematic diagram of the nanosecond diffuse reflectance laser flash photolysis apparatus to produce and detect transient absorptions in light-scattering samples. 
inserted into the signal input socket of the digital oscilloscope. The transient decay is then recorded by the oscilloscope as a voltage change, and the data points are recalculated to the final signal $\Delta J$ according to:

$$
\Delta J=\frac{J_{0} / I_{0}-J_{x} / I_{0}}{J_{0} / I_{0}}=\frac{J_{0}-J_{x}}{J_{0}}
$$

where $I_{0}$ is the incident intensity of the analyzing light; $J_{0}$ is the diffusely reflected light without laser pulse (ground light level); $J_{x}$ is the diffusely reflected light with the laser pulse.

It has been reported that the $\Delta J$ value can be correlated with the transient absorption if $\Delta J$ is less than $0.1,{ }^{18}$ thus to describe the results obtained by the detection of the diffuse reflected light the term transient absorption will be employed.

A dry powder in a flat quartz cuvette has been used in all diffuse reflectance experiments. Herewith, the illumination area of the laser beam and of the analyzing light is $0.5 \mathrm{~cm}^{2}$ and $0.196 \mathrm{~cm}^{2}$, respectively. For measurements with a $\mathrm{N}_{2}$-methanol atmosphere, a few drops were added, and the powder was dried with $\mathrm{N}_{2}$.

\section{Results and discussion}

\section{Irradiation of phase-pure $\mathrm{Ba}_{5} \mathrm{Ta}_{4} \mathrm{O}_{15}$}

$\mathrm{Ba}_{5} \mathrm{Ta}_{4} \mathrm{O}_{15}$ has a very large band gap of $4.5 \mathrm{eV}$. Irradiation was therefore performed with a $248 \mathrm{~nm}$ laser pulse. Measuring the initial signal height immediately after the laser pulse, with the powder being kept under an inert $\mathrm{N}_{2}$ atmosphere, two very broad transient absorption maxima centred at around $650 \mathrm{~nm}$ and at around $430 \mathrm{~nm}$ can be observed, together with a third distinct absorption increase at $310 \mathrm{~nm}$ (Fig. 2a).

In $\mathrm{TiO}_{2}$ nanomaterials, transient absorption signals observed in the range of $600 \mathrm{~nm}$ to $650 \mathrm{~nm}$ are attributed to trapped electrons. ${ }^{14,19}$ Kobayashi has investigated tantalates by means of dual-beam picosecond absorption spectroscopy and obtained for $\mathrm{LiTaO}_{3}$ a transient absorption maximum at around $650 \mathrm{~nm} .^{15}$ This transient absorption has been related to photo-induced colour complex centres. ${ }^{15,16}$ The rise in absorption at $310 \mathrm{~nm}$ is not comparable to $\mathrm{TiO}_{2}$, whereas the transient absorption observed between $400 \mathrm{~nm}$ and $530 \mathrm{~nm}$ is attributed to the trapped holes. ${ }^{14,19,20}$ Usually, the trapped holes are identified as $\mathrm{O}^{\bullet-} / \bullet \mathrm{OH}$ radicals. Free $\mathrm{O}^{\bullet-} /{ }^{\bullet} \mathrm{OH}$ radicals show a transient absorption at $266 \mathrm{~nm} .{ }^{21}$ If the radicals are bound at the metal oxide surface its electrochemical environment is changed and thus a shift of the absorption is expected. In the case of $\mathrm{TiO}_{2}$ a red shift of the transient absorption by $100 \mathrm{~nm}$ has been reported. ${ }^{22}$ Regarding the large band gap of the investigated material $\mathrm{Ba}_{5} \mathrm{Ta}_{4} \mathrm{O}_{15}$, the transient absorption at around $310 \mathrm{~nm}$ might be attributed to holes trapped above the valence band (VB).

In addition, Fig. 2a shows the transient absorption spectra measured at different times after the laser pulse. Within the first $\mu$ s the transient absorption spectra do not change, while $4.5 \mu \mathrm{s}$ after the laser pulse the transient absorption maximum at around $650 \mathrm{~nm}$ disappears and a broad absorption spectrum with a slightly pronounced maximum at around $430 \mathrm{~nm}$ remains.

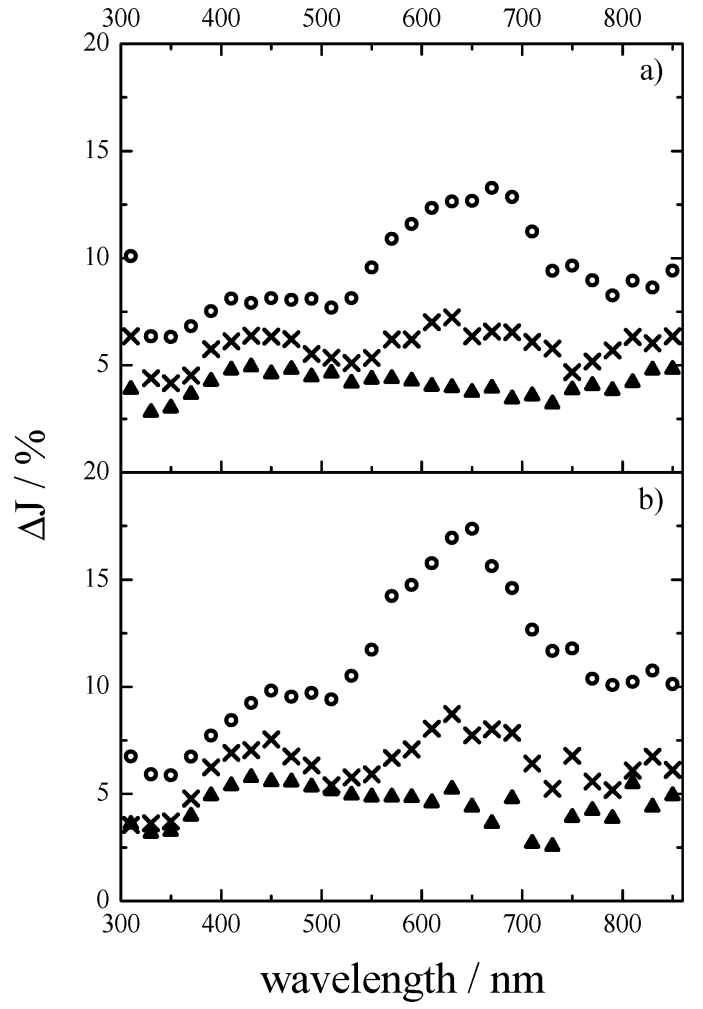

Fig. 2 Transient absorption spectra of $\mathrm{Ba}_{5} \mathrm{Ta}_{4} \mathrm{O}_{15}$ powders measured $80 \mathrm{~ns}$ (circles), $0.6 \mu \mathrm{s}$ (crosses) and $4.5 \mu \mathrm{s}$ (triangles) after laser excitation $\left(\lambda_{\text {ex }}=248 \mathrm{~nm}\right.$ ) in a $\mathrm{N}_{2}$ (a) and a $\mathrm{N}_{2}$-methanol (b) atmosphere.

In order to relate the observed transient absorption signals to possible trapped charge carriers, we performed the same measurements in a $\mathrm{N}_{2}$-methanol environment, to investigate the changes in the transient spectra. In the presence of methanol the absorptions at $650 \mathrm{~nm}$ and $430 \mathrm{~nm}$ strongly increase, while the absorption at $310 \mathrm{~nm}$ deteriorates (see Fig. 2b). This indicates that the latter can actually be attributed to trapped holes, which react rapidly with methanol (see eqn (5)), resulting in a strongly decreased absorption signal after the laser pulse compared to the pure $\mathrm{N}_{2}$ atmosphere. For example, holes photogenerated in $\mathrm{TiO}_{2}$ are scavenged with methanol within $1 \mathrm{~ns} .^{23}$ Thus, since the holes have reacted with methanol, the probability of electron-hole recombination is reduced and the absorption signal for the electrons increases compared to the $\mathrm{N}_{2}$ atmosphere, in which the likelihood of electron-hole recombinations is considerably higher. Consequently, the signals at $650 \mathrm{~nm}$ and $430 \mathrm{~nm}$ can be attributed to trapped electrons in $\mathrm{Ba}_{5} \mathrm{Ta}_{4} \mathrm{O}_{15}$. From the time evolution of the transient spectra it can be concluded that the maximum at around $430 \mathrm{~nm}$ belongs to more deeply trapped electrons, since it remains even at $4.5 \mu$ s after the laser pulse, while the transient absorption maximum at around $650 \mathrm{~nm}$ disappears, similar to the transient absorption spectra obtained in a $\mathrm{N}_{2}$-atmosphere.

Fig. 3 shows the transient absorption kinetics at (a) $650 \mathrm{~nm}$ and (b) $310 \mathrm{~nm}$ in a $\mathrm{N}_{2}$-atmosphere (black curves) and in the presence of $\mathrm{N}_{2}$-methanol (red curves), respectively. As can be seen for both signals, a strong increase in absorption is 


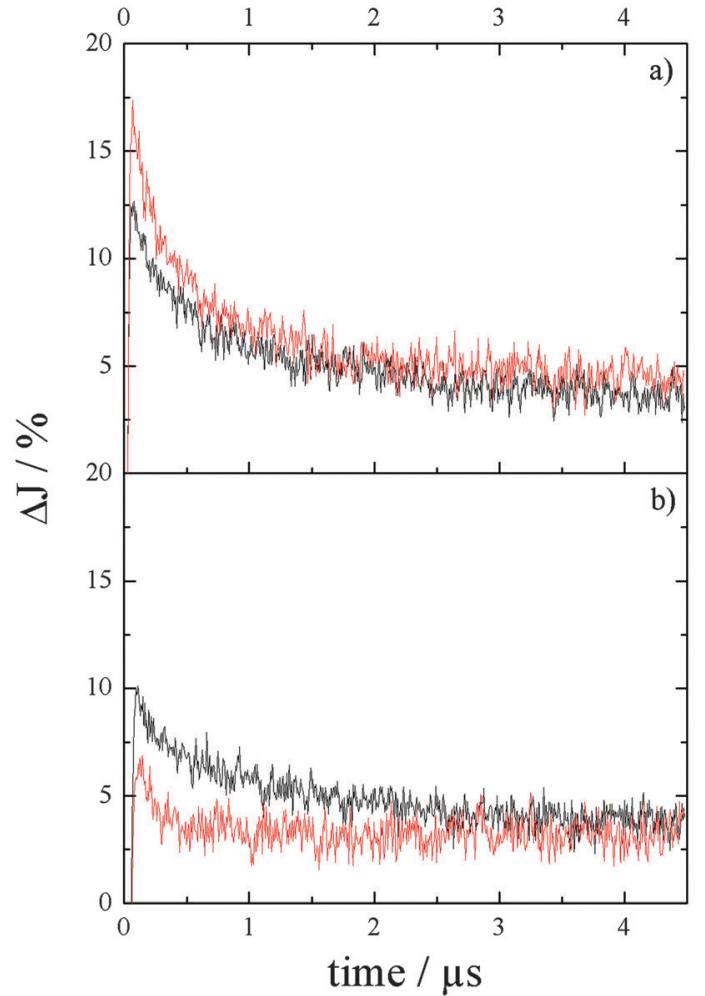

Fig. 3 Transient absorption vs. time curves of phase-pure $\mathrm{Ba}_{5} \mathrm{Ta}_{4} \mathrm{O}_{15}$ in a $\mathrm{N}_{2}$ (black) and a $\mathrm{N}_{2}-$ methanol (red) atmosphere, $\lambda_{\mathrm{ex}}=248 \mathrm{~nm}$, at $650 \mathrm{~nm}$ (a) and $310 \mathrm{~nm}$ (b).

apparent immediately after the laser pulse, which decreases rapidly in the first $\sim 250 \mathrm{~ns}$, thereafter reaching a long-lasting, nearly constant absorption. The initial absorption $J_{0}$ of the signal at $650 \mathrm{~nm}$ is higher than at $310 \mathrm{~nm}$, while the decay kinetics of both signals are similar. The characteristic time after which $J_{0}$ decays to $J_{0} / e(\sim 37 \%)$ is $\sim 0.7 \pm 0.1 \mu \mathrm{s}$. This characteristic time has been determined for the recalculated decays, in which the constant absorption after $4.5 \mu$ s has been subtracted from the detected $\Delta J$. This allows more accurate comparison of the decay kinetics and has been applied for all further data analysis. Moreover, the decay kinetics have been analysed for all wavelengths in the range between $310 \mathrm{~nm}$ and $850 \mathrm{~nm}$ resulting in similar decay behaviour with a $t_{1 / e}$ value of $0.7 \pm 0.1 \mu \mathrm{s}$.

Comparing the transient absorption kinetics at $650 \mathrm{~nm}$ and $310 \mathrm{~nm}$ in the presence of methanol (see Fig. $3 \mathrm{a}$ and b (red)), the decay at $650 \mathrm{~nm}$ shows a slightly longer life time following a strong decrease in absorption during the first $100 \mathrm{~ns}$ after the laser pulse. However, $37 \%(1 / e)$ of the initial absorption is reached after $0.45 \mu \mathrm{s}$, while in $\mathrm{N}_{2}$ this value is reached after $0.7 \mu$ s (Fig. 3a). This means that in the presence of methanol the recombination of charge carriers could not be suppressed. It may be due to the fact that the methanol molecule reacts only with the surface trapped holes, while the bulk carriers remain in the system and recombine with trapped electrons. In general, a decrease rather than a complete disappearance of the transient absorption signal at $310 \mathrm{~nm}$ is observed. After $4 \mu \mathrm{s}$, in all atmospheres the observed transient absorption at $650 \mathrm{~nm}$ reaches a nearly constant plateau, but only in $\mathrm{N}_{2}$-methanol the absorption stays a little bit higher compared to the pure nitrogen system.

In contrast, the transient absorption at $310 \mathrm{~nm}$ decays fastest in $\mathrm{N}_{2}$-methanol and reaches $J_{0} / e$ already after $0.26 \mu \mathrm{s}$ (Fig. $3 \mathrm{~b}$ (red)), while it prevails longer in $\mathrm{N}_{2}$. This is in accordance with our assumption that this absorption can be attributed to trapped holes reacting with methanol (see eqn (5)), leading to a fast decay of the absorption.

\section{Charge carriers in $\mathrm{Ba}_{5} \mathrm{Ta}_{4} \mathrm{O}_{15}-\mathrm{Ba}_{3} \mathrm{Ta}_{5} \mathrm{O}_{15}$ composites}

As already mentioned, $\mathrm{Ba}_{5} \mathrm{Ta}_{4} \mathrm{O}_{15}-\mathrm{Ba}_{3} \mathrm{Ta}_{5} \mathrm{O}_{15}$ composites exhibit improved photocatalytic performance for molecular $\mathrm{H}_{2}$ generation compared to phase-pure $\mathrm{Ba}_{5} \mathrm{Ta}_{4} \mathrm{O}_{15}$, both without co-catalysts. This fact was explained by the calculated band positions, indicating a probable electron transfer after excitation increasing the electron lifetimes in the composite. ${ }^{10}$

A $248 \mathrm{~nm}$ laser pulse was again used to excite the composite powders, and to determine the wavelength-dependent transient absorption right after excitation in inert $\mathrm{N}_{2}$. Comparable to the phase pure $\mathrm{Ba}_{5} \mathrm{Ta}_{4} \mathrm{O}_{15}$ powder (Fig. 2a), the composite shows $80 \mathrm{~ns}$ after the laser pulse a broad transient absorption at around $650 \mathrm{~nm}$, and an even stronger absorption at $310 \mathrm{~nm}$, while in contrast to the pure material the maximum at around $430 \mathrm{~nm}$ is less pronounced (Fig. 4a). Moreover, the transient

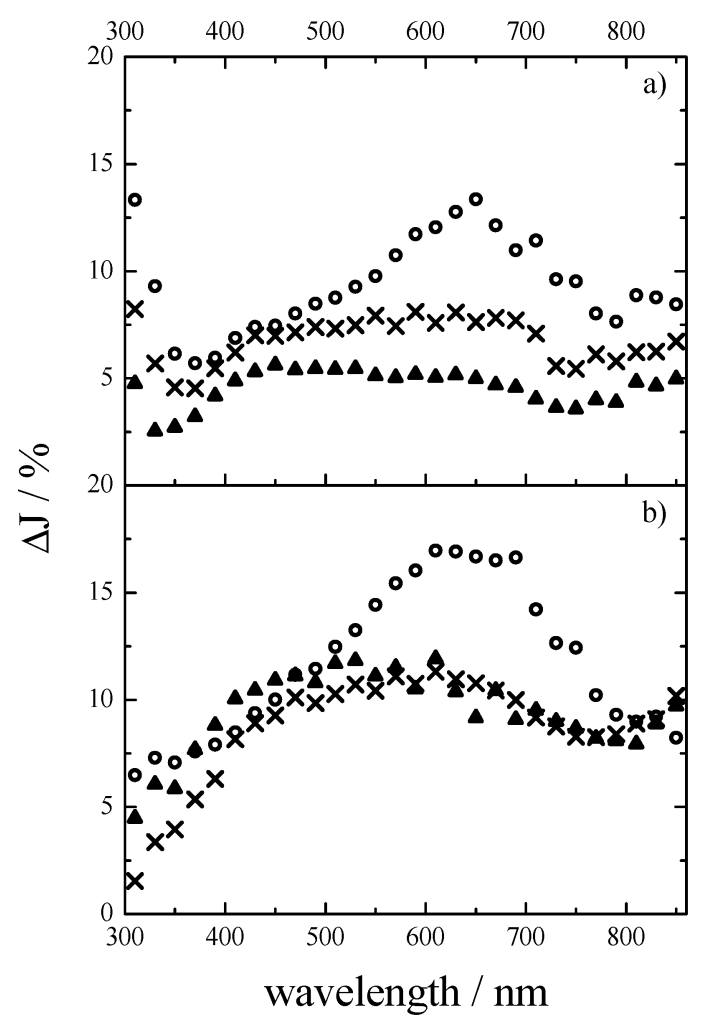

Fig. 4 Transient absorption spectra of $\mathrm{Ba}_{5} \mathrm{Ta}_{4} \mathrm{O}_{15}-\mathrm{Ba}_{3} \mathrm{Ta}_{5} \mathrm{O}_{15}$ composite powders measured $80 \mathrm{~ns}$ (circles), $0.6 \mu$ s (crosses) and $4.5 \mu$ s (triangles) after laser excitation $\left(\lambda_{\mathrm{ex}}=248 \mathrm{~nm}\right)$ in a $N_{2}$ (a) and a $\mathrm{N}_{2}$-methanol (b) atmosphere. 
absorption spectrum changes with the decay time. Already $0.6 \mu \mathrm{s}$ after the laser pulse a broad and featureless absorption in the wavelength range between $350 \mathrm{~nm}$ and $710 \mathrm{~nm}$ is observed, while the maximum at $310 \mathrm{~nm}$ remains. The broadness of the spectra can be explained by the fact that in the composite the charge carriers, mainly the electrons, are distributed at different trapping states within the band gap.

It is not surprising that similar transient absorption signals can be determined for the composite, since the formation of electron-hole pairs in the composite will generate the same kind of excited species, e.g., $\mathrm{Ta}^{4+}, \mathrm{F}^{+}$- and F-centers (see eqn (2) and (3)). Although the crystal structure of the two components is slightly different (hexagonal layered perovskite vs. tetragonal), tantalum is surrounded by 6 oxygen atoms in both structures, and the resulting $\mathrm{TaO}_{6}$ octahedra are corner-sharing. However, it is obvious that the transient absorption at $310 \mathrm{~nm}$, which was attributed to holes in the phase-pure material and most likely also in the composite material investigated here, is nearly as high as the electron signal at $650 \mathrm{~nm}$, in contrast to the phase pure material.

Fig. 4b shows the changes in transient absorption after the laser pulse when the composite powders were measured changing the atmosphere to $\mathrm{N}_{2}$-methanol. In the presence of methanol 80 ns after the laser pulse the transient absorption at $310 \mathrm{~nm}$ disappears again completely, indicating the oxidation of methanol via the trapped holes followed by the decrease of their absorption state. The transient absorption at around $650 \mathrm{~nm}$ increases strongly in a $\mathrm{N}_{2}$-methanol atmosphere, revealing the transient absorption of trapped electrons in the composite. The transient absorption spectra alter with the decay time, namely, a new transient absorption maximum at around $500 \mathrm{~nm}$ appears and remains even $4.5 \mu$ s after the laser pulse. This stability of the transient spectra differs from the transient spectra obtained for the phase-pure $\mathrm{Ba}_{5} \mathrm{Ta}_{4} \mathrm{O}_{15}$ thus conveying the ability of the composite to store the electrons, which can be subsequently used for reduction reactions, i.e., the generation of $\mathrm{H}_{2}$.

The transient absorption decay curves obtained at $650 \mathrm{~nm}$ and $310 \mathrm{~nm}$ in the absence of any electron acceptor or donor are shown in Fig. $5 \mathrm{a}$ and $\mathrm{b}$ (black curves). The initial absorption $J_{0}$ and the $t_{1 / e}$ values of the signals at $310 \mathrm{~nm}$ and at $650 \mathrm{~nm}$ are similar. $J_{0}$ decays to $J_{0} / e$ within $0.7 \pm 0.1 \mu \mathrm{s}$ as has also been found for the pure phase. Nevertheless, the long-lasting, nearly constant transient absorption is higher in comparison to the pure phase tantalate indicating that the two absorbing species have longer lifetimes in the composite as compared with the phase-pure $\mathrm{Ba}_{5} \mathrm{Ta}_{4} \mathrm{O}_{15}$.

The red curves in Fig. 5a and b demonstrate the transient absorption decay of the two most pronounced absorption states in the composite powders in the presence of methanol. In a $\mathrm{N}_{2}$-methanol atmosphere the decay kinetics at $650 \mathrm{~nm}$ change drastically (Fig. 5a, red curve). Following the sharp rise in absorption immediately after the laser pulse and a rapid decay within the first $500 \mathrm{~ns}$, the absorption rises again slightly reaching a maximum at around $2.2 \mu \mathrm{s}$, then levelling slowly off, however, being always much higher than the signal in pure

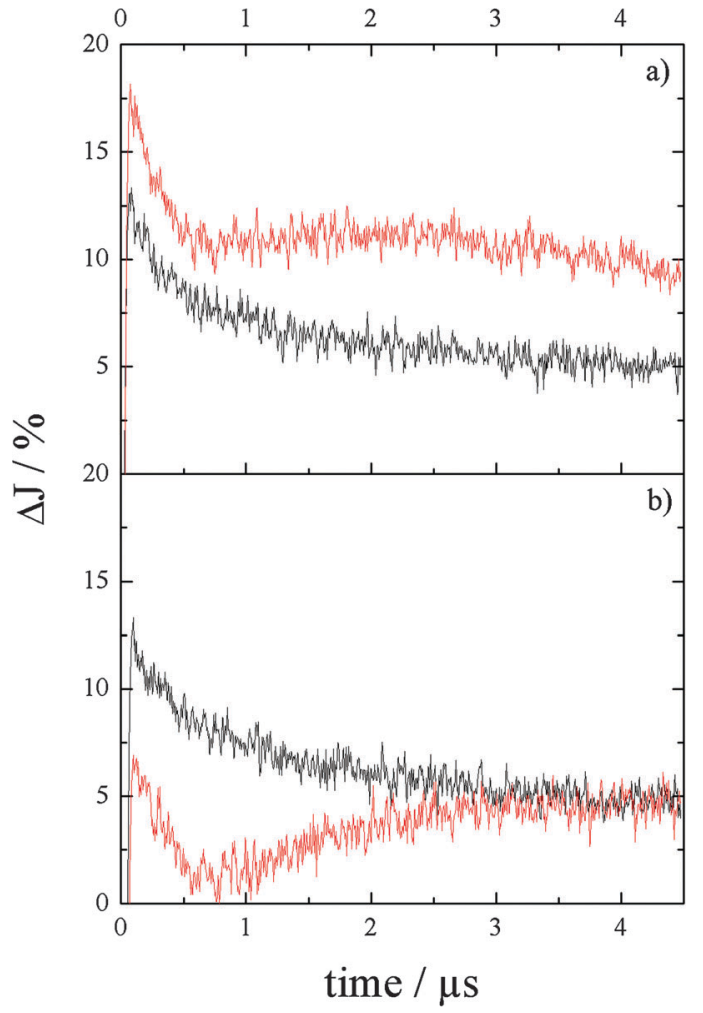

Fig. 5 Transient absorption vs. time curves of $\mathrm{Ba}_{5} \mathrm{Ta}_{4} \mathrm{O}_{15}-\mathrm{Ba}_{3} \mathrm{Ta}_{5} \mathrm{O}_{15}$ composite powders in a $\mathrm{N}_{2}$ (black) and a $\mathrm{N}_{2}$-methanol (red) atmosphere, $\lambda_{\text {ex }}=248 \mathrm{~nm}$, at (a) $650 \mathrm{~nm}$ and (b) $310 \mathrm{~nm}$.

$\mathrm{N}_{2}$. The rapid decay of the transient at $310 \mathrm{~nm}$ (Fig. 5b, red curve) within $500 \mathrm{~ns}$ evinces the reaction of the trapped hole with methanol. The following build-up indicates the formation of a new species exhibiting a transient absorption in the UV region, which may correspond to complex defects of the type: $\mathrm{Ta}^{4+}: \mathrm{Ta}^{4+} x \mathrm{O}_{\mathrm{v}} x \mathrm{Ta}^{4+}$, as it has been proposed by Antonov et al. ${ }^{16 a}$ for the absorption bands at around 450 and $550 \mathrm{~nm}$.

The recombination of the charge carriers in the composite in the presence of methanol could be sufficiently reduced in contrast to the phase pure $\mathrm{Ba}_{5} \mathrm{Ta}_{4} \mathrm{O}_{15}$. Compared to Fig. 3a, in which the lifetime of electrons was slightly decreased, in the composite the transient absorption signal remains high even longer after the laser pulse, indicating an accumulation of the electrons in the system. Since both transients are very different, it is reasonable to argue charge carrier trapping in the composite after charge excitation gives rise to this behaviour. The main difference in the materials investigated is the second component $\mathrm{Ba}_{3} \mathrm{Ta}_{5} \mathrm{O}_{15}$ exhibiting a more anodic conduction band position $\left(-0.5 \mathrm{~V}\right.$ vs. NHE) than $\mathrm{Ba}_{5} \mathrm{Ta}_{4} \mathrm{O}_{15}(-1.2 \mathrm{~V}$ vs. NHE). Thus, it is likely that electrons are transferred onto this second component and are trapped there. This also explains the initial absorption decays, followed by a slow build-up of the transient absorption over time. The electrons on $\mathrm{Ba}_{5} \mathrm{Ta}_{4} \mathrm{O}_{15}$ can still recombine, as shown in Fig. 3a, but when they are transferred to $\mathrm{Ba}_{3} \mathrm{Ta}_{5} \mathrm{O}_{15}$, they accumulate and are trapped. To prove this behaviour, it would be useful to investigate phase pure $\mathrm{Ba}_{3} \mathrm{Ta}_{5} \mathrm{O}_{15}$, but preparation in pure form was not possible yet. 
Charge carrier dynamics in the presence and absence of electron donors: pure $\mathrm{Ba}_{5} \mathrm{Ta}_{4} \mathrm{O}_{15}$ vs. composite $\mathrm{Ba}_{5} \mathrm{Ta}_{4} \mathrm{O}_{15}-\mathrm{Ba}_{3} \mathrm{Ta}_{5} \mathrm{O}_{15}$

In many reports the transient absorption decay curves of the trapped charge carriers in $\mathrm{TiO}_{2}$ have been described employing second order reaction kinetics according to the bimolecular recombination of the electron-hole pairs coupled by Coulombic forces. ${ }^{24}$ Rothenberger et al. proposed for $\mathrm{TiO}_{2}$ a recombination process on the picosecond time scale involving trapped electrons and free valence band holes, while on the nanosecond time scale the participation of trapped holes in the recombination process was suggested. ${ }^{14 d}$

The transient decay signals obtained for tantalates in a $\mathrm{N}_{2}$ atmosphere on the microsecond time scale could be successfully fitted by second order reaction kinetics:

$$
\Delta J_{\mathrm{m}}(t)=\frac{J_{0}}{k_{\mathrm{r}} \cdot J_{0} \cdot t+1}
$$

assuming the recombination of the trapped electrons (transient absorption signals at $650 \mathrm{~nm}$ and $430 \mathrm{~nm}$ ) with the trapped

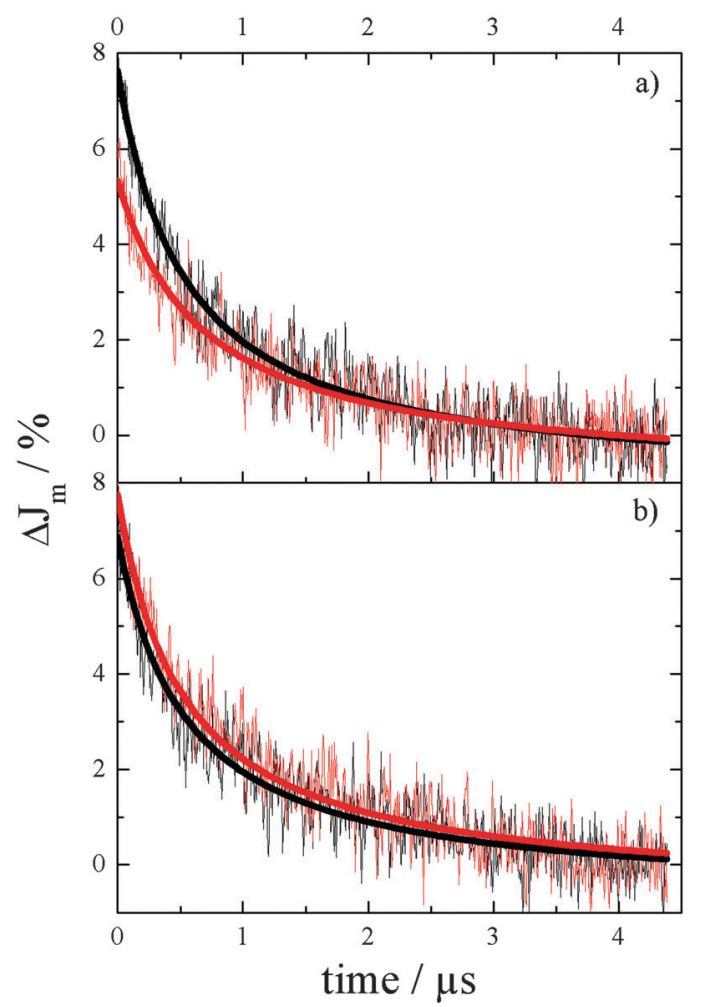

Fig. 6 Modified transient absorption kinetics of phase-pure $\mathrm{Ba}_{5} \mathrm{Ta}_{4} \mathrm{O}_{15}$ powders (a) and $\mathrm{Ba}_{5} \mathrm{Ta}_{4} \mathrm{O}_{15}-\mathrm{Ba}_{3} \mathrm{Ta}_{5} \mathrm{O}_{15}$ composites (b) in a $\mathrm{N}_{2}$ atmosphere at $650 \mathrm{~nm}$ (black) and $310 \mathrm{~nm}$ (red). holes (transient absorption at $310 \mathrm{~nm})$ :

$$
\mathrm{e}_{\mathrm{tr}}{ }^{-}+\mathrm{h}_{\mathrm{tr}}+\stackrel{k_{\mathrm{r}}}{\longrightarrow} \text { heat }
$$

The observed long-lived component of the transient absorption follows more complicated non-second-order reaction kinetics thus for a better comparison of the initial decay behavior at different wavelengths, this plateau absorbance has been subtracted from the absorption decay. Moreover, the initial signal intensity has been set to $t=0$ according to:

$$
\Delta J_{\mathrm{m}}(t)=\Delta J(t+80 \mathrm{~ns})-\Delta J(t=4.5 \mu \mathrm{s})
$$

Fig. $6 \mathrm{a}$ and $\mathrm{b}$ present the decay curves together with the fit for (a) the phase-pure and (b) the composite material, respectively. The obtained recombination rate constant and the initial transient absorption change are summarized in Table 1. Since the extinction coefficient of the trapped species is unknown, it is not possible to determine the absolute concentrations of the species and thus to derive the absolute values for the recombination constants. For both, phase pure $\mathrm{Ba}_{5} \mathrm{Ta}_{4} \mathrm{O}_{15}$ and the $\mathrm{Ba}_{5} \mathrm{Ta}_{4} \mathrm{O}_{15}-\mathrm{Ba}_{3} \mathrm{Ta}_{5} \mathrm{O}_{15}$ composite, a rate constant value of around $2 \times 10^{5}(\mathrm{~s} \%)^{-1}$ has been obtained evincing that the recombination rate does not depend on the composition of the tantalate powders. The assumed improved charge separation in the composite material could not be verified in the absence of any electron donor or acceptor. Moreover, the rate constant is found to be wavelength independent thus confirming the above assumption that the decay is due to the recombination between two trapped species. Although the transient absorption of the trapped electrons is very broad indicating the existence of energetically different trapped electrons, the latter recombine with the same rate with the trapped holes.

The decay kinetics of the transients for the phase pure material and for the composite in the presence of methanol differ from each other. As can be seen in Fig. 3, in the presence of methanol no build-up of the transient absorption as in the case of $\mathrm{TiO}_{2}$ is obtained, ${ }^{14 b}$ in contrast an accelerated decay at $650 \mathrm{~nm}$ occurs. Upon the reaction of the holes with methanol, - $\mathrm{CH}_{2} \mathrm{OH}$ radicals are formed. It has been reported that these radicals can also act as a recombination centers. ${ }^{20 b, 25}$ Since the conduction band of $\mathrm{Ba}_{5} \mathrm{Ta}_{4} \mathrm{O}_{15}$ is more negative $(-1.2 \mathrm{~V}$ vs. NHE) than the reduction potential of the ${ }^{\bullet} \mathrm{CH}_{2} \mathrm{OH}$ radical $(-0.739 \mathrm{~V} v s$. NHE $),{ }^{26}$ the latter is not able to inject an electron into the conduction band, i.e., a current-doubling process is energetically not possible here. In the absence of molecular $\mathrm{O}_{2} \cdot \mathrm{CH}_{2} \mathrm{OH}$ radicals will rather be reduced again by the trapped electrons effectively resulting in an overall $\mathrm{e}^{-} / \mathrm{h}^{+}$recombination. In fact, the reaction of trapped electrons with ${ }^{\bullet} \mathrm{CH}_{2} \mathrm{OH}$ radicals

\begin{tabular}{|c|c|c|c|c|}
\hline & \multicolumn{2}{|l|}{ Phase-pure $\mathrm{Ba}_{5} \mathrm{Ta}_{4} \mathrm{O}_{15}$} & \multicolumn{2}{|c|}{$\mathrm{Ba}_{5} \mathrm{Ta}_{4} \mathrm{O}_{15}-\mathrm{Ba}_{3} \mathrm{Ta}_{5} \mathrm{O}_{15}$ composite } \\
\hline$\lambda_{\mathrm{A}}[\mathrm{nm}]$ & 650 & 310 & 650 & 310 \\
\hline $\begin{array}{l}J_{0}[\%] \\
k_{\mathrm{r}}\left[\mathrm{s}^{-1} \%\right]\end{array}$ & $\begin{array}{l}8.7 \pm 0.1 \\
(2.14 \pm 0.09) \times 10^{5}\end{array}$ & $\begin{array}{l}6.23 \pm 0.09 \\
(2.4 \pm 0.2) \times 10^{5}\end{array}$ & $\begin{array}{l}7.6 \pm 0.1 \\
(2.4 \pm 0.1) \times 10^{5}\end{array}$ & $\begin{array}{l}8.4 \pm 0.1 \\
(2.3 \pm 0.1) \times 10^{5}\end{array}$ \\
\hline
\end{tabular}
should be regarded as an electron coupled proton transfer

Table 1 Fitting parameters such as initial transient absorption $J_{0}$ and rate constant $k_{\mathrm{r}}$ of the decay observed at certain analysing wavelength $\lambda_{\mathrm{A}}$ 

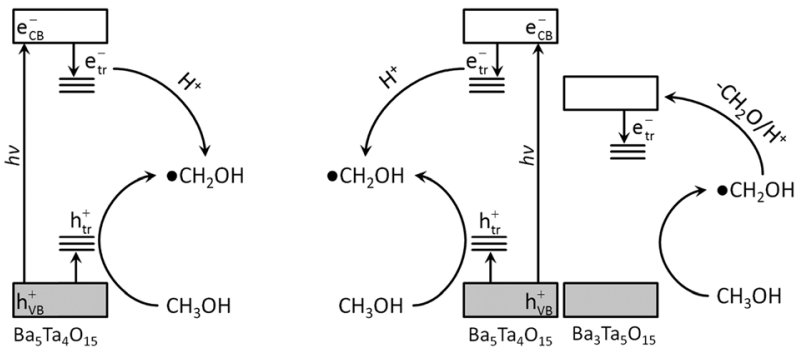

Fig. 7 Proposed mechanism for the photo-induced processes in phasepure $\mathrm{Ba}_{5} \mathrm{Ta}_{4} \mathrm{O}_{15}$ powders (left) and in $\mathrm{Ba}_{5} \mathrm{Ta}_{4} \mathrm{O}_{15}-\mathrm{Ba}_{3} \mathrm{Ta}_{5} \mathrm{O}_{15}$ composites (right) in a $\mathrm{N}_{2}$-methanol atmosphere, comparable to photocatalytic experiments.

yielding $\mathrm{CH}_{3} \mathrm{OH}$ rather than the pure electron transfer (see Fig. 7 left). ${ }^{27}$ However, in the case of a $\mathrm{Ba}_{5} \mathrm{Ta}_{4} \mathrm{O}_{15}-\mathrm{Ba}_{3} \mathrm{Ta}_{5} \mathrm{O}_{15}$ composite the $\alpha$-hydroxy-methyl radical can inject an electron into the energetically favorable conduction band of $\mathrm{Ba}_{3} \mathrm{Ta}_{5} \mathrm{O}_{15}$ $(-0.5 \mathrm{~V}$ vs. NHE). Hence, during the first $0.6 \mu$ s the reaction of the trapped electrons in $\mathrm{Ba}_{5} \mathrm{Ta}_{4} \mathrm{O}_{15}$ with ${ }^{\bullet} \mathrm{CH}_{2} \mathrm{OH}$ is observed followed by the formation of more deeply trapped electrons in $\mathrm{Ba}_{3} \mathrm{Ta}_{5} \mathrm{O}_{15}$ (see Fig. 7 right). Consequently, in the transient absorption spectra (Fig. 4b) a new band is observed $0.6 \mu \mathrm{s}$ after the laser pulse, related to trapped electrons in $\mathrm{Ba}_{3} \mathrm{Ta}_{5} \mathrm{O}_{15}$. In contrast to the phase pure powder the photogenerated electrons in the composite powder can thus be stored for reduction processes, which explains the higher photocatalytic performance for $\mathrm{H}_{2}$ generation under comparable conditions of the composite material, supporting the earlier drawn assumption of the concerted charge carrier transfer process in these composites. $^{10}$

\section{Conclusions}

Two pronounced transient absorption maxima at $310 \mathrm{~nm}$ and $650 \mathrm{~nm}$ have been found for $\mathrm{Ba}_{5} \mathrm{Ta}_{4} \mathrm{O}_{15}$ and for a composite of $\mathrm{Ba}_{5} \mathrm{Ta}_{4} \mathrm{O}_{15}-\mathrm{Ba}_{3} \mathrm{Ta}_{5} \mathrm{O}_{15}$. The experiments performed in the presence of an electron donor such as methanol allowed for the first time to attribute these transient absorptions to trapped holes and electrons, respectively, with the former absorbing in the UV range while the latter absorbs in the visible light range. The transient absorption at $650 \mathrm{~nm}$ can be related to $\mathrm{Ta}^{4+}$, as it has been proposed earlier for $\mathrm{LiTaO}_{3}$.

The analysis of the transient absorption signals revealed that the decay kinetics do not depend on the absorption wavelength. This means that the detected trapped electrons and holes react only with each other. They can reach one another through a hopping mechanism, similar to the one that has been observed for $\mathrm{TiO}_{2}$.

By comparison of the pure tantalate with the composite, it is obvious that the composite exhibits higher amounts of long lived charge carriers under a $\mathrm{N}_{2}$-methanol atmosphere. Moreover, the recombination of the charge carriers could be sufficiently reduced and an accumulation of the trapped electrons could be detected. A model explaining the different behaviours of the pure phase and the composite material was proposed, with either ${ }^{\bullet} \mathrm{CH}_{2} \mathrm{OH}$ acting as a recombination center in phase-pure tantalate, or involving additional electron injection into the composite material (current doubling). This model explains the improved performance of the composite in photocatalytic hydrogen generation experiments, which has been reported previously.

\section{Acknowledgements}

We thank Julia Soldat, Ruhr-University Bochum, for providing the two samples. D. W. B. and R. M. acknowledge financial support from the BMBF (Bundesministerium für Bildung und Forschung), research project DuaSol (03SF0482C and 03SF0482D). R. M. gratefully acknowledges funding from the Emmy-Noether program (MA 5392/3-1) of the German Research Foundation DFG. M. W. acknowledges financial support from the DFG (WA 1116/28). The work carried out in Hannover (Germany) was supported by the Global Research Laboratory (GRL) Program (NRF-2014K1A1A2041044) funded by the Korea government (MSIP) through NSF. The present study was performed within the Project "Establishment of the Laboratory Photoactive Nanocomposite Materials" no. 14.Z50.31.0016 supported by a Mega-grant of the Government of the Russian Federation.

\section{Notes and references}

1 N. S. Lewis and D. G. Nocera, Proc. Natl. Acad. Sci. U. S. A., 2006, 103, 15729.

2 A. Kudo and Y. Miseki, Chem. Soc. Rev., 2009, 38, 253.

3 X. Chen, S. Shen, L. Guo and S. S. Mao, Chem. Rev., 2010, 110, 6503.

4 J. Schneider, M. Matsuoka, M. Takeuchi, J. Zhang, Y. Horiuchi, M. Anpo and D. W. Bahnemann, Chem. Rev., 2014, 114, 9919.

5 (a) T. A. Kandiel, R. Dillert, L. Robben and D. W. Bahnemann, Catal. Today, 2011, 161, 196; (b) T. A. Kandiel, A. A. Ismail and D. W. Bahnemann, Phys. Chem. Chem. Phys., 2011, 13, 20155.

6 T. A. Kandiel, I. Ivanova and D. W. Bahnemann, Energy Environ. Sci., 2014, 7, 1420.

7 Y. Tamaki, A. Furube, M. Murai, K. Hara, R. Katoh and M. Tachiya, J. Am. Chem. Soc., 2006, 128, 416.

8 M. R. Hoffmann, S. T. Martin, W. Choi and D. W. Bahnemann, Chem. Rev., 1995, 95, 69.

9 (a) B. Ohtani, O. O. Prieto-Mahaney, D. Li and R. Abe, J. Photochem. Photobiol., A, 2010, 216, 179; (b) R. Marschall, Adv. Funct. Mater., 2014, 24, 2421.

10 R. Marschall, J. Soldat, G. W. Busser and M. Wark, Photochem. Photobiol. Sci., 2013, 12, 671.

11 H. Otsuka, K. Kim, A. Kouzu, I. Takimoto, H. Fujimori, Y. Sakata, H. Imamura, T. Matsumoto and K. Today, Chem. Lett., 2005, 34, 822.

12 A. Mukherji, C. Sun, S. C Smith, G. Q. Lu and L. Wang, J. Phys. Chem. C, 2011, 115, 15674. 
13 J.-J. Huang, Y.-J. Hsiao, T.-H. Fang and T.-H. Chen, J. Sol-Gel Sci. Technol., 2012, 62, 75.

14 (a) D. Duonghong, J. Ramsden and M. Grätzel, J. Am. Chem. Soc., 1982, 104, 2917; (b) D. Bahnemann, A. Henglein, J. Lilie and L. Spanhel, J. Phys. Chem., 1984, 88, 709; (c) D. Bahnemann, A. Henglein and L. Spanhel, Faraday Discuss. Chem. Soc., 1984, 78, 151; (d) G. Rothenberger, J. Moser, M. Grätzel, N. Serpone and D. K. Sharma, J. Am. Chem. Soc., 1985, 107, 8054; (e) D. W. Bahnemann, M. Hilgendorff and R. Memming, J. Phys. Chem. B, 1997, 101, 4265.

15 T. Kobayashi, Solid State Commun., 1980, 33, 95.

16 (a) V. A. Antonov, P. A. Arsenev, I. G. Linda and V. L. Farstendiker, Phys. Status Solidi A, 1975, 28, 673; (b) L. A. Kappers, K. L. Sweeney, L. E. Halliburton and J. H. W. Liaw, Phys. Rev. B: Condens. Matter Mater. Phys., 1985, 31, 6792.

17 J. Schneider and D. W. Bahnemann, J. Phys. Chem. Lett., 2013, 4, 3479.

18 (a) T.-P. Lin and H. K. A. Kan, J. Opt. Soc. Am., 1970, 60, 1252; (b) R. W. Kessler, G. Krabichler, S. Uhl, D. Oelkrug, W. P. Hagan, J. Hyslop and F. Wilkinson, Optica Acta: International Journal of Optics, 1983, 30, 1099.

19 Y. Murakami, J. Nishino, T. Mesaki and Y. Nosaka, Spectrosc. Lett., 2011, 44, 88.

20 (a) X. Wang, A. Kafizas, X. Li, S. J. A. Moniz, P. J. T. Reardon, J. Tang, I. P. Parkin and J. R. Durrant, J. Phys. Chem. C, 2015, 119, 10439; (b) X. Yang and N. Tamai, Phys. Chem. Chem. Phys., 2001, 3, 3393; (c) T. Yoshihara, Y. Tamaki, A. Furube,
M. Murai, K. Hara and R. Katoh, Chem. Phys. Lett., 2007, 438, 268; (d) Y. Tamaki, A. Furube, M. Murai, K. Hara, R. Katoh and M. Tachiya, Phys. Chem. Chem. Phys., 2007, 9, 1453; (e) R. Katoh, M. Murai and A. Furube, Chem. Phys. Lett., 2010, 500, 309; $(f)$ J. Tang, A. J. Cowan, J. R. Durrant and D. R. Klug, J. Phys. Chem. C, 2011, 115, 3143; ( $g$ ) L. Jing, J. Zhou, J. R. Durrant, J. Tang, D. Liu and H. Fu, Energy Environ. Sci., 2012, 5, 6552.

21 G. L. Hug, Optical Spectra of Nonmetallic Inorganic Transient Species in Aqueous Solution, NSRDS-NBS, 1981, 69.

22 D. Lawless, N. Serpone and D. Meisel, J. Phys. Chem., 1991, 95, 5166.

23 Y. Tamaki, A. Furube, M. Murai, K. Hara, R. Katoh and M. Tachiya, J. Am. Chem. Soc., 2006, 128, 416.

24 (a) N. Serpone, D. Lawless, R. Khairutdinov and E. Pelizzetti, J. Phys. Chem., 1995, 99, 16655; (b) D. P. Colombo and R. M. Bowman, J. Phys. Chem., 1996, 100, 18445; (c) D. P. Colombo and R. M. Bowman, J. Phys. Chem., 1995, 99, 11752; (d) D. E. Skinner, D. P. Colombo, J. J. Cavaleri and R. M. Bowman, J. Phys. Chem., 1995, 99, 7853; (e) A. Furube, T. Asahi, H. Masuhara, H. Yamashita and M. Anpo, J. Phys. Chem. B, 1999, 103, 3120.

25 J. Rabani, K. Yamashita, K. Ushida, J. Stark and A. Kira, J. Phys. Chem. B, 1998, 102, 1689.

26 J. Lilie, G. Beck and A. Henglein, Ber. Bunsenges. Phys. Chem., 1971, 75, 458.

27 J. N. Schrauben, R. Hayoun, C. N. Valdez, M. Braten, L. Fridley and J. M. Mayer, Science, 2012, 336, 1298. 